Bulletin of Pharmaceutical Sciences
Assiut University
Website: http://bpsa.journals.ekb.eg/
e-mail: bullpharm@aun.edu.eg

\title{
PHENOTYPING CYP3A4/5 USING AN ENDOGENOUS BIOMARKER IN CHILDREN WITH DOWN SYNDROME
}

\author{
Zoheir A. Damanhouri ${ }^{1}$, Ahmed S. Ali ${ }^{1,2^{*}}$, Jumana Y. AlAama ${ }^{3}$, Fuad Y. Almaweri ${ }^{1}$, \\ Alaa M. Khedr ${ }^{4}$ and Lateef M. Khan ${ }^{1}$ \\ ${ }^{1}$ Department of Pharmacology, Faculty of Medicine, King Abdulaziz University (KAU), Saudi \\ Arabia \\ ${ }^{2}$ Department of Pharmaceutics, Faculty of Pharmacy, Assiut University, Assiut, Egypt \\ ${ }^{3}$ Princess Al-Jawhara Center of Excellence in Research of Hereditary Disorders, King \\ Abdulaziz University (KAU), Saudi Arabia \\ ${ }^{4}$ Departmentt of Pharmaceutical Chemistry, Faculty of Pharmacy, King Abdulaziz \\ University (KAU), Saudi Arabia
}

\begin{abstract}
Background: Down syndrome (DS); a common chromosomal abnormality in humans can affect multiple organ systems. DS individuals usually use a wide range of medications. There is a gap in knowledge about the extent of contribution of CYP3A4/5 in altered clinical response to medications in DS children.

Objectives: Phenotyping of CYP3A4/5 in DS children using. the ratio of $4 \beta$-hydroxycholesterol / Cholesterol (4 $\beta-O H C / C)$ as an endogenous biomarker for $C Y P 3 A 4 / 5$ activity.

Method: The study was an observational case control study, conducted in the DS clinic, King Abdul-Aziz University Hospital. Blood samples were taken for thyroid and liver function test by automated immunoassay procedure and analysis of cholesterol and $4 \beta$-hydroxycholesterol by gas chromatography.

Results: 16 DS and 29 non-DS children were enrolled (1-12 Y). Children with DS showed a lower median $4 \beta$-OHC/C molar ratio of $0.19 \times 10^{-4}$ compared to $0.45 \times 10^{-4}$ in the control group and with interquartile range (IQR) $0.17,0.36$ respectively $(p<0.001$ Mann Whitney $U$ test). DS children also showed an abnormality in liver enzymes and hypercholesteremia.

Conclusion: Children with DS had about two-fold lower CYP3A4/5 activity compared to children without DS. More studies to confirm these observations are required, however, drugs should be used cautiously in DS children.
\end{abstract}

\section{INTRODUCTION}

Down syndrome (DS) is one of the most common genetic disorders, and an epidemiological study of children in Saudi Arabia showed an incidence of 18 per $10,000^{1}$. It is known that DS patients suffer many health problems that require the use of $\mathrm{drugs}^{2}$, and many studies have shown that these patients have an altered clinical response compared to non-DS patients ${ }^{3-7}$.

A major source of variability in drug clinical response can be attributed to the difference in drug-metabolizing enzymes
(DMEs), especially cytochrome P450 3A4 and 3A5 (CYP3A4/5) which metabolizes more than $50 \%$ of all marketed drugs ${ }^{8-10}$. The clinical relevance of genetic and non-genetic factors that influence CYP-mediated metabolism can be appreciated by estimating in-vivo enzyme activity (i.e., the phenotyping) through the use of "probe drugs" or by using an endogenous biomarker" ${ }^{11}$.

Cytochrome P450 phenotyping provides information about their activity; It can be assessed by administration of $a$ sub-therapeutic dose of the probe $\operatorname{drug}(\mathrm{s})$ which are the substrate for the intended CYP450. Blood or 
urine samples are collected and sometimes saliva for drug/ metabolites analysis by chromatography ${ }^{12 \& 13}$. Due to the limitations of this approach increasing interest was given for utilizing endogenous biomarkers in the phenotyping of drug-metabolizing enzymes. In this context, the metabolite of cholesterol e.g. $4 \beta-O H C$ reflects the activity of CYP3A $4 / 5$ so it was utilized as an endogenous biomarker for phenotyping of activity of these enzymes ${ }^{14-16}$. Studies deals with phenotyping Cytochrome P450 in DS are very limited. Therefore, we conducted the present study to demonstrate the difference in CYP3A4/5 activity between children with and non-DS children.

\section{MATERIALS AND METHODS}

\section{Settings}

The study was implemented at the DS clinic, King Abdul-Aziz University Hospital (KAUH), the study protocol was approved by the Research Ethics Committee of the Faculty of Medicine, (KAU). The study was approved by the Unit of biomedical ethics Faculty of Medicine at King Abdul-Aziz University. (Ref 378-10). Consent was taken from children's parents to be voluntarily involved in the study.

\section{Sample size determination}

The sample size was estimated using the following parameters: $\mathrm{SD}=25 \mathrm{ng} / \mathrm{ml}$ and $p=$ 0.05 two-sided The sample size in each group $\cong 16$

$$
n=\frac{2\left(Z_{\frac{\alpha}{2}}+Z_{\beta}\right)^{2} \times S D^{2}}{d^{2}}
$$

Taking into account down syndrome is a relatively rare disease, this number is satisfactory to provide a reliable conclusion $^{17 \& 18}$.

Regarding sample size, 16 DS children enrolled in the study was considered sufficient to provide a reliable conclusion regarding children with the relatively rare congenital disorder as the prevalence of DS in KSA $(18 / 10.000)$ as suggested by a Consultant biostatistician.

\section{Inclusion criteria}

Sixteen healthy children with DS and 26 healthy controls in the age range of 1-12 years were enrolled from KAUH. All children with
DS underwent cytogenetic analysis and had trisomy 21. (All children are Arab residents in Makkah region of SA).

\section{Exclusion criteria}

History of hepatic dysfunction; two siblings; congestive heart failure and using prescribed drugs that are known to induce or inhibit CYP3A4/5.

\section{Samples collection and storage}

Single venous blood sample $(1-2 \mathrm{ml})$ ordered as part of routine clinical care) was withdrawn in EDTA-tubes from each subject. Samples were centrifuged and serum was separated for routine biochemical analysis. The remaining serum was kept at $-80^{\circ} \mathrm{C}$ until GCMS analysis for determination of total cholesterol and $4 \beta-\mathrm{OHC}$ was done.

\section{Biochemical analysis}

Serum thyroid-stimulating hormone (TSH) and free triiodothyronine (FT3) were analyzed at KAUH, biochemistry lab via the cobas ${ }^{\mathrm{TM}}$ clinical chemistry system (Roche Diagnostics, Germany). The method is an immunoassay for the in-vitro quantitative determination of TSH and FT3 in the serum. It is done by two incubations assays of the sample using the sandwich principle for TSH and the competition principle for FT3. The first incubation is to form an immunocomplex and the second is to bind the complex to a solid phase. After unbound substances are removed the reaction mixture is aspirated magnetically onto an electrode, a photomultiplier is used to measure a voltage induced emission. Results are determined via a calibration curve. Albumin (Alb), and liver function tests Alanine transaminase (ALT); Aspartate transaminase (AST), were done by Dimension Clinical Chemistry System (Stream lab.). Calibration and analysis were done as specified by the reagent manufacturer. The lab joined an external quality control program to ensure high quality of analytical results.

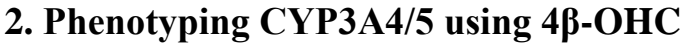

The ratio of $4 \beta-\mathrm{OHC} /$ Cholesterol in serum was used as an endogenous probe for CYP3A4/5 activity ${ }^{19}$. 


\section{Chromatography analysis}

The concentrations of cholesterol and $4 \beta$ $\mathrm{OHC}$ were determined in each serum sample according to reported methods with slight modification $^{20}$. The serum samples were thawed at room temperature, $250 \mu \mathrm{L}$ was transferred to an autosampler $1.8 \mathrm{~mL}$ vial by auto-pipette, mixed with $250 \mu \mathrm{L} 2 \mathrm{M} \mathrm{KOH}$ (prepared in water), then was capped and vortexed for $2 \mathrm{sec}$., and allowed to stand at room temperature for $20 \mathrm{~min}$ (to hydrolyze combined cholesterol or its hydroxyl forms). The whole amount of serum was transferred by Pasteur pipette to the $\mathrm{C} 8$ extraction column, a vacuum was started and half a milliliter of distilled water was added for washing. The vacuum was then applied for $10 \mathrm{~min}$ to evaporate the water. The elution solution consisted of $1 \mathrm{~mL}$ solvent composed of $80 \%$ ethyl acetate and 20\% n-hexane and $1 \mathrm{~mL}$ $\mathrm{CH}_{2} \mathrm{Cl}_{2}$ was added. This extraction solution was then dried under dry Nitrogen gas at $40^{\circ} \mathrm{C}$. Twenty-five microliter MSTFA was added (using silanized glass syringe) to the remaining residue and was heated at $80^{\circ} \mathrm{C}$ for $35 \mathrm{~min}$ (half inserted at thermostated block heater). One microliter was injected for GC-MS (GC-MS Clarus 5000 (Perkin Elmer), analysis using the programmed split-split less mode, after leaving the vial to cool to room temperature. $4 \beta$ $\mathrm{OHC} / \mathrm{C}$ was calculated as a molar ratio by dividing the molar concentration of $4 \beta-\mathrm{OHC}$ by the molar concentration of cholesterol (Molecular weight; 402.65 and $386.65 \mathrm{~g} / \mathrm{mol}$ of $4 \beta-\mathrm{OHC}$ and cholesterol respectively).

\section{Statistical analysis}

All data were statistically processed with the SPSS program, version 16.0 (SPSS Inc., Chicago, IL, USA). Data when show normal distribution are presented as mean \pm S.E (standard error of the mean) to evaluate confidence interval or \pm SD (Standard deviation) to express the extent of variability. Median (IQR) is used in case of absence of normal distribution.

The normal distribution of variables was checked with the Shapiro-Wilk test. MannWhitney U-test was used to compare $4 \beta$ $\mathrm{OHC} / \mathrm{C}$ between groups because the groups have deviated from the normal distribution. For all tests, values of $p<0.05$ (two-tailed) were considered statistically significant. To assess if there is any cofounding factor, the study of the correlation between both age, gender, and thyroid function (TSH and FT3) and the molar ratio was done using the Spearman correlation test. Ethnicity was not considered confounding factors as all children are Arab most of them are Saudi.

\section{RESULTS}

\section{Chromatographic analysis}

Figure 1 represents the (EI) GCMS chromatogram. The analytical procedure was validated; the limit of quantification (LOQ) $(n=$ 5) of $0.4 \mathrm{ng} / \mathrm{ml}$ and 0.8 for $4 \beta-\mathrm{OHC}$ and cholesterol in serum was obtained, respectively. At the LOQ, the RSD $(n=3)$ of the measured concentration was $5.2 \%$ and $7.1 \%$ respectively, and the accuracy of measurement was $7.2 \%$.

\section{Summary of demographic and relevant data}

Sixteen DS individuals (50\% males, $50 \%$ females) and 29 non-DS (41\% males, 59\% females) were included in the study; All are Arab population, most are Saudi.

None of the non-DS subjects was on medications that were known substrates, inhibitors, or inducers of CYP3A. Six DS children were on thyroxin therapy, non of them use other medications that may induce or inhibit CYP3A4/5.

\section{Thyroid function}

The results of thyroid function are shown in figure 2 and the results of liver function are shown in figure 3 for both DS and non-DS children. DS individuals showed a significantly lower mean value of FT3 \pm SD; $5.8 \pm 0.24$ ( $\mathrm{pmol} / \mathrm{L})$ compared to non-DS children $6.5 \pm 0.15(\mathrm{pmol} / \mathrm{L}), \quad(p=0.025)$; while they showed a higher mean TSH value of $4.1 \pm 0.7$ ( $\mu \mathrm{IU} / \mathrm{L})$ compared to $2.9 \pm 0.3$ ( $\mu \mathrm{IU} / \mathrm{L}$ ) in nonDS children. The latter result is statistically insignificant $(p=0.112)$. Correlations between both FT3 and TSH versus $4 \beta-\mathrm{OHC} / \mathrm{C}$ ratio were studied using Spearman correlation coefficient, no significant correlation was observed. DS individuals showed significantly higher mean values of (ALT, AST, ) and lower mean Alb compared to non-DS (Fig. 3). Using Spearman's correlation test no significant correlation between the $4 \beta-\mathrm{OHC} / \mathrm{C}$ ratio with either liver enzymes or age was observed in tables $1 \& 2$. 


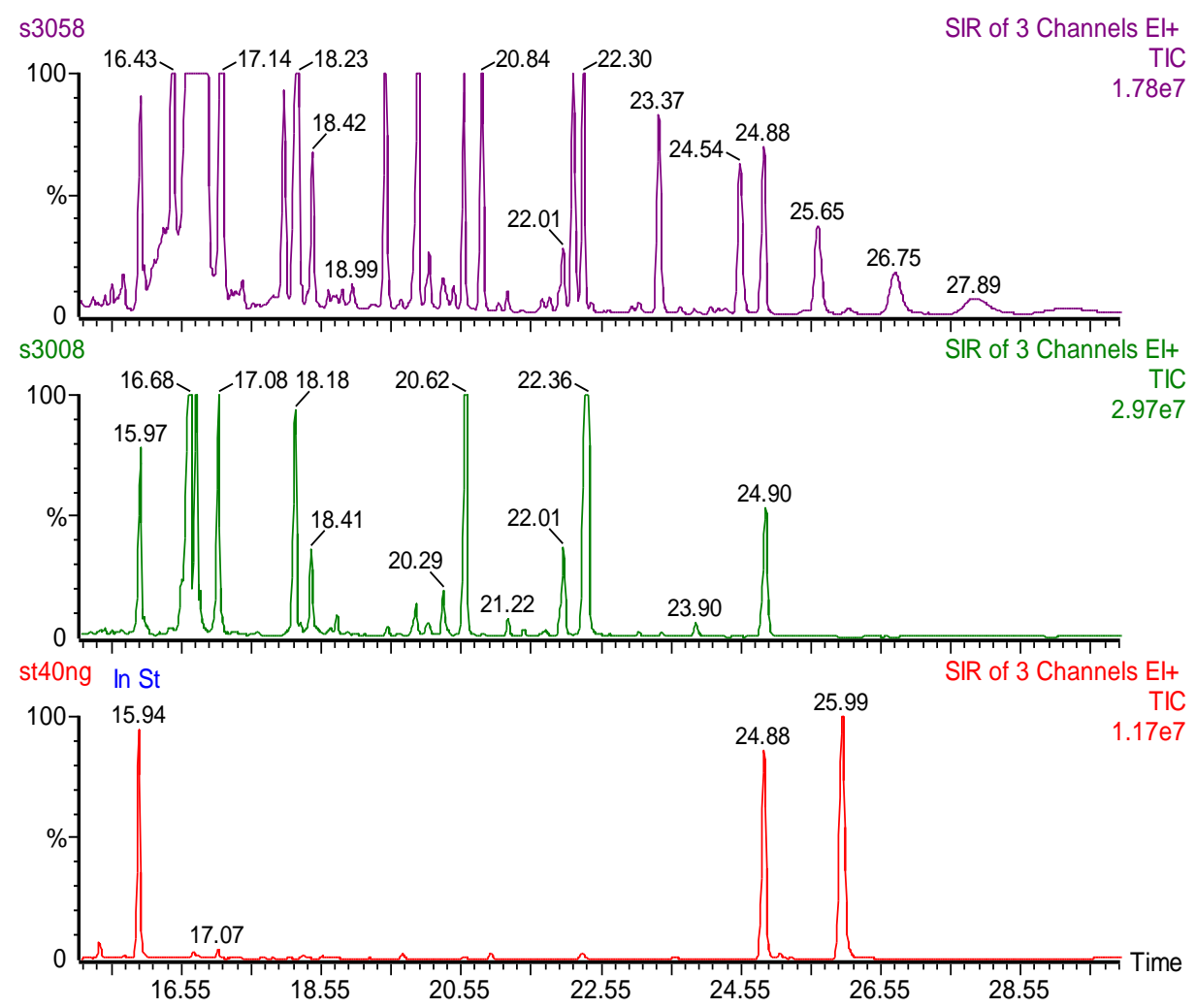

Fig. 1: GC-EI-MS chromatogram of; (A) and (B) two different non-DS samples, (C) cholesterol, 4ß-OHC, and internal standards. All are MSTFA derivatized.

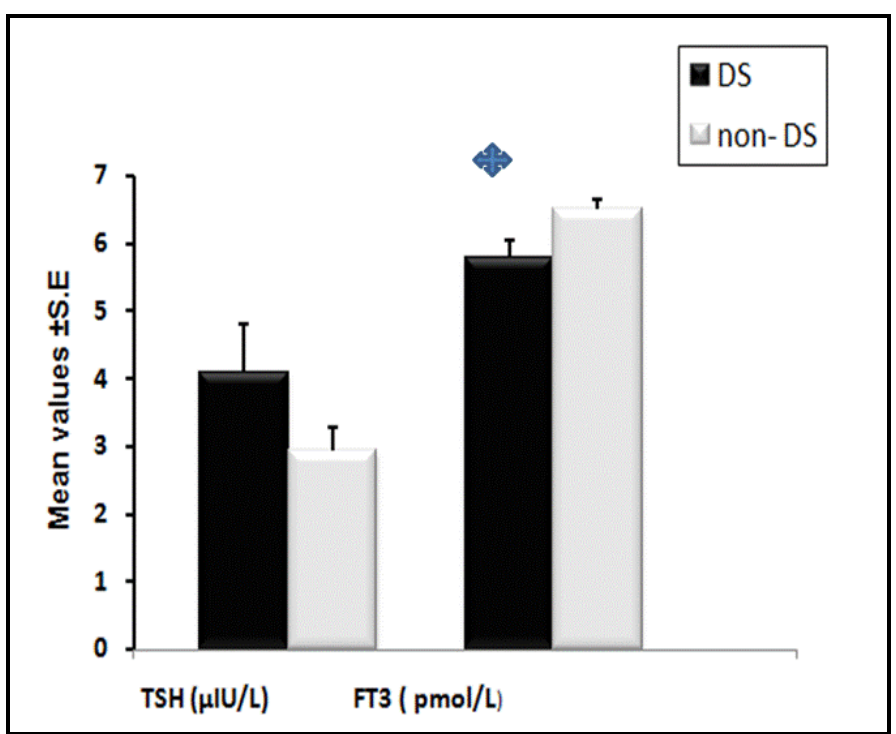

Fig. 2: Mean values of serum TSH and FT3 in DS and non DS children.

TSH: Thyroid-stimulating hormone, FT3: Free triiodothyronine,

*Significantly different from control ( $\mathrm{p}<0.05$, Mann Whitney U test). 


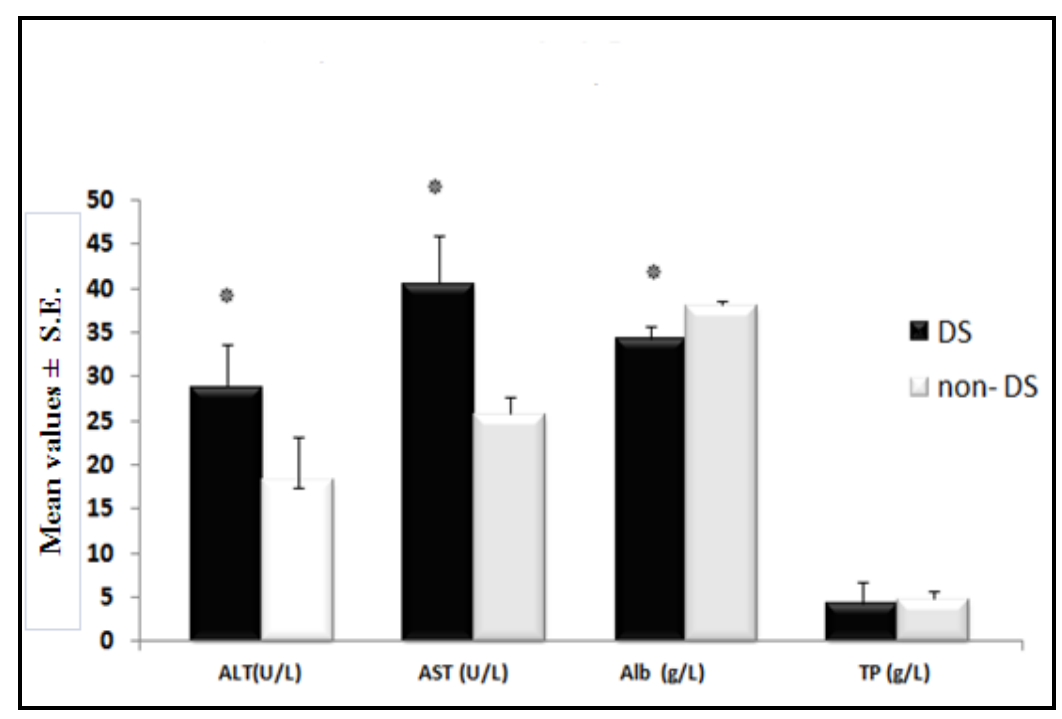

Fig. 3: Mean values $( \pm$ S.E) of liver function in Down syndrome (DS) and non-DS children (control).

ALT: Alanine aminotransferase; AST: Aspartate aminotransferase, Alb: Fig albumin, TP: Total protein. *Significantly different from control ( $\mathrm{p}<0.05$, Mann Whitney U test).

Table 1: Correlations of some biochemical parameters with $4 \beta-\mathrm{OHC} / \mathrm{C}$ ratio in DS using Spearman's coefficient.

\begin{tabular}{|c|l|c|c|c|c|c|c|c|}
\hline & & Age & FT3 & TSH & ALT & AST & Alb & TP \\
\hline RATIO & $\begin{array}{l}\text { Correlation } \\
\text { coefficient }\end{array}$ & 0.144 & $0.545^{*}$ & -0.113 & -0.012 & 0.209 & -0.052 & -0.072 \\
\hline & Sig. (2-tailed) & 0.594 & 0.029 & 0.676 & 0.968 & 0.494 & 0.854 & 0.799 \\
\hline & $\mathrm{N}$ & 16 & 16 & 16 & 13 & 13 & 15 & 15 \\
\hline
\end{tabular}

*Correlation is significant at the 0.05 level (2-tailed).

Table 2: Correlations of some biochemical parameters with $4 \beta-\mathrm{OHC} / \mathrm{C}$ ratio in non-DS using Spearman's correlation coefficient.

\begin{tabular}{|l|l|c|c|c|c|c|c|c|}
\hline \hline & & Age & FT3 & TSH & ALT & AST & Alb & TP \\
\hline RATIO & $\begin{array}{l}\text { Correlation } \\
\text { coefficient }\end{array}$ & 0.020 & -0.198 & -0.325 & -0.122 & -0.271 & 0.360 & 0.343 \\
\hline & Sig. (2-tailed) & 0.921 & 0.303 & 0.086 & 0.529 & 0.155 & 0.055 & 0.068 \\
\hline & N & 29 & 29 & 29 & 29 & 29 & 29 & 29 \\
\hline
\end{tabular}

*Correlation is significant at the 0.05 level (2-tailed). 


\section{Serum total cholesterol levels}

The median (IQR) serum concentration of total cholesterol showed a significantly higher value in DS4.06 (3.09) compared to Non-DS $2.18(1.4)(\mathrm{ng} / \mathrm{ml})$ with $p<0.0001$. There is no significant difference observed between males and females. Hypercholesteremia was observed in about $40 \%$ of DS (total serum Cholesterol $>5 \mathrm{mM}$ ).

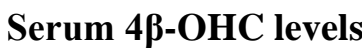

The median (IQR) $(\mathrm{ng} / \mathrm{ml})$ of $4 \beta-\mathrm{OHC}$ in non-DS and DS is 30.7 and 40.8 , respectively. A trend for lower median $4 \beta-\mathrm{OHC}$ is noticed in DS $(p=0.07)$ in comparison with non-DS.

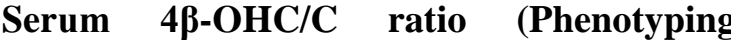 biomarker)}

Table 3 shows the serum $4 \beta-\mathrm{OHC} / \mathrm{C}$ represented as median (IQR) in both groups. The DS children have a less varied and significantly lower value of $4 \beta-\mathrm{OHC} / \mathrm{C}$ $\left(0.19 \times 10^{-4}\right)$ compared to the non DS control children with corresponding value of $(0.45 \times$ $\left.10^{-4}\right), \quad(p<0.0001)$. Figure 4 shows the frequency of $4 \beta-\mathrm{OHC} / \mathrm{C}$ ratio in the serum of DS and non-DS children. DS children showed a more variable $4 \beta-\mathrm{OHC} / \mathrm{C}$ ratio, the range $[0.15$ $0.85] \times 10^{-4}$. In contrast, children with DS showed lower variability in $4 \beta-\mathrm{OHC} / \mathrm{C}$, the range $[0.05-0.35] \times 10^{-4}$. Neither gender nor thyroxine therapy showed a statistically significant effect on $4 \beta-\mathrm{OHC} / \mathrm{C}$ ratio in DSChildren.

Table 3: Serum $4 \beta-\mathrm{OHC} / \mathrm{C}$ ratio $\times 10^{-4}$ in DS and non-DS.

\begin{tabular}{|c|c|c|c|c|c|}
\hline Comparing* & & $\begin{array}{c}\text { Median } \\
\text { (IQR) }\end{array}$ & $\mathrm{CV} \%$ & $95 \% \mathrm{CI}$ & $\mathrm{P}^{*}$ \\
\hline \multirow{2}{*}{ DS vs. Non-DS } & $\begin{array}{l}\text { DS } \\
n=16\end{array}$ & $0.19(0.17)$ & 66.67 & $0.14-0.28$ & \multirow{2}{*}{$<0.001 * *$} \\
\hline & $\begin{array}{l}\text { Non-DS } \\
n=29\end{array}$ & $0.45(0.36)$ & 66.07 & $0.41-0.70$ & \\
\hline \multirow{2}{*}{$\begin{array}{l}\text { DS } \\
\text { (Gender) }\end{array}$} & $\begin{array}{l}\text { Male } \\
n=8\end{array}$ & $0.21(0.13)$ & 45.00 & $0.13-0.28$ & \multirow{2}{*}{0.833} \\
\hline & $\begin{array}{l}\text { Female } \\
n=8\end{array}$ & $0.16(0.19)$ & 81.81 & $0.07-0.37$ & \\
\hline \multirow{2}{*}{$\begin{array}{l}\text { Non-DS } \\
\text { (Gender) }\end{array}$} & $\begin{array}{l}\text { Male } \\
n=12\end{array}$ & $0.48(0.45)$ & 65.57 & $0.36-0.86$ & \multirow{2}{*}{0.425} \\
\hline & $\begin{array}{l}\text { Female } \\
n=17\end{array}$ & $0.41(0.36)$ & 71.15 & $0.33-0.71$ & \\
\hline
\end{tabular}

DS; Down syndrome. Non-DS; Children. CI; Confidence interval. $4 \beta-\mathrm{OHC} / \mathrm{C}$; $4 \beta$-hydroxycholesterol/cholesterol; coefficient of variation. IQR; Interquartile range.

*Significant differences (Mann Whitney U test). 


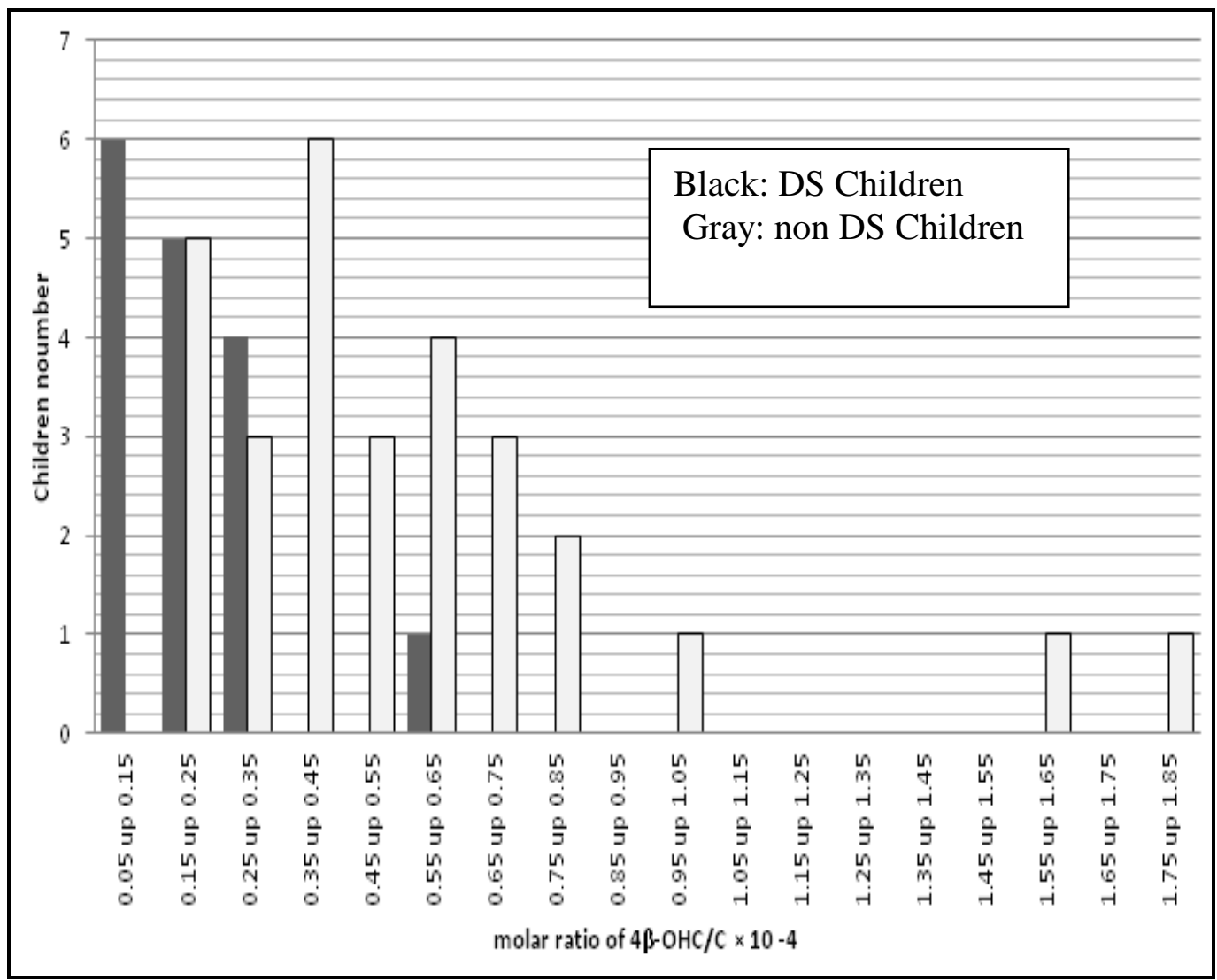

Fig. 4: The distribution and the cumulative frequency of $4 \beta-\mathrm{OHC} / \mathrm{C}$ ratio concentrations in serum of DS and non DS children.

\section{DISCUSSION}

Altered drug response is frequently observed in DS individuals which may be due to pharmacokinetics, pharmacodynamics; genetics, or other variables. There is a gap in knowledge regarding the contribution of liver metabolizing enzyme in these variabilities. This study tried to use an endogenous biomarker to predicate the activity of one of the most important Phase I drug metabolizing enzymes, namely CYP3A4/5. Other variables including thyroid function will be also addressed.

In this study, no correlation between liver function parameters (ALT, AST) and the molar ratio of the $4 \beta-\mathrm{OHC} / \mathrm{C}$ ratio was observed in both DS and non-DS children. Mild elevation in ALT, AST, and lower Alb was observed in DS children compared to non-DS children. Elevated liver enzymes, in DS children, may be explained by multiple factors, including obesity, low activity, sleep apnea, thyroid abnormality low vitamin $\mathrm{D}$; glutathione deficiency, and increase in oxidative stress ${ }^{21}$.
Dyslipidemia in DS children was common $^{22}$; Unachak et al. ${ }^{23}$ pointed out that sub-clinical hypothyroidism was the most common thyroid abnormality in children with DS the thyroid hormone, FT3 has a positive effect on the binding of LDL to its receptor. Hypothyroidism was suggested as a contributing factor in hypercholesterolemia ${ }^{24}$. Given this background and increase in $\mathrm{TSH}$ (Fig. 2) in our study, we suggested a potential link between subclinical hypothyroidism and hypercholesteremic in DS-Children. Recently the occurrence of dyslipidemia in DS was not associated with over-nutritional obesity ${ }^{22}$.

Interest is increasing regarding use of endogenous biomarkers for phenotyping of CYP450 activity, in this context, $4 \beta \mathrm{OHC} / \mathrm{C}$ was frequently used ${ }^{14,15 \& 25}$. In our study, we found a significant difference in FT3 between DS and non-DS $p<0.05$, but there was no correlation between FT3 with either $4 \beta-\mathrm{OHC}$ or $4 \beta-\mathrm{OHC} / \mathrm{C}$ (using Spearman correlation test), this indicates that FT3 is not a confounding factor in our phenotyping CYP3A4/5. 
Some studies have shown that body weight is negatively correlated with $4 \beta \mathrm{OHC} / \mathrm{C}$ ratio in healthy volunteers ${ }^{25}$ and that obese patients have lower $4 \beta \mathrm{OHC}$ levels than healthy controls $^{26}$. Studies on the clearance of several other CYP3A substrates suggest that CYP3A activity is reduced by $10-35 \%$ in obese patients $^{27}$. Further-more, Ulvestad et al. ${ }^{28}$ reported a strong negative correlation between body mass index (BMI) and CYP3A protein expression in the liver and intestines ${ }^{28}$. Altogether, this indicates that CYP3A activity decreases with increasing body weight. In our study, DS children expected to have higher BMI compared to non DS which may contribute to the observed lower CYP450 activity.

In the case of high interpatient variability in the measured serum cholesterol levels, the ratio of $4 \beta-\mathrm{OHC} / \mathrm{C}$ should be used as a marker for CYP3A4/5 activity ${ }^{19}$.

Concerning $4 \beta-\mathrm{OHC} / \mathrm{C}$ molar ratio in both DS and non-DS, the median (IQR) in DS was $0.19(0.17)\left(\times 10^{-4}\right)$, while in non-DS the corresponding value was $\left(0.45 \times 10^{-4}\right)$ (Table 3$)$. The DS group exhibited a significantly lower median molar ratio $(p<0.001)$ compared to non-DS. No significant difference between females and males in CYP3A4/5 activity in DS or non-DS was observed.

Based on the above findings, we suggested that DS children exhibited lower CYP3A4/5 activity compared to non-DS children. Our finding supports and explains the reduced clearance of certain drugs whose metabolism is mediated by CYP3A4. Palle et al. ${ }^{29}$ reported lower median etoposide clearance in DS children $\left(13.6 \mathrm{ml} / \mathrm{min} / \mathrm{m}^{2}\right)$ compared to that of non DS children $\left(17.6 \mathrm{ml} / \mathrm{min} / \mathrm{m}^{2}\right)$.

A study done by Zwaan et al..$^{30}$ confirmed that cells of DS children with Acute myeloid leukemia (AML), AML possess greater sensitivity to several chemotherapeutic agents such as cytarabine, etoposide, busulfan, and prednisolone. These studies did not explain the higher incidence of adverse effects in DS children. The disposition of all the previously mentioned drugs involves CYP 450 metabolism ${ }^{31-34}$. Given our findings of low CYP3A4/5 activity in DS children, we strongly suggest that reduced clearance of chemotherapeutic drugs in DS has a major contribution to both a better prognosis and a higher incidence of adverse effects to chemotherapeutic agents which are the substrate for CYP3A4/5 enzymes.

Infants with DS showed prolonged theophylline clearance ${ }^{35}$. Theophylline metabolism in the liver is known to be mainly mediated by CYP1A2 while at higher plasma concentrations CYP2E1 is also involved ${ }^{36}$. We suggested that CYP1A2 and CYP2E possibly have reduced activity. in DS patients that require further investigations.

\section{Limitations}

The study has limitations of not determining the body weight at the time of sampling; and lack of genotyping analysis of CYP3A4/5.

\section{Conclusion}

CYP3A4/5 activity was determined by using $4 \beta-\mathrm{OHC} / \mathrm{C}$ in DS and non-DS children, non-DS children show 2.4 fold higher CYP3A4/5 activity comparing to DS. We recommend that special precaution with medications that depend on CYP3A4/5 should be followed in DS children. Further studies are needed to phenotype other CYPs in DS, as well as genotyping of these enzymes.

\section{Acknowledgment}

The authors acknowledge the dean of Scientific research - King Abdulaziz University KSA for funding this project. They also acknowledge the Princess Al-Jawhara Center of Excellence in Research of Hereditary Disorders, Jeddah, KAU, KSA for providing all facilities to conduct the work.

\section{REFERENCES}

1- A. Alsalloum, M. I. El Mouzan, A. Alherbish, A. Alomer and M. Qurashi, "Prevalence of selected congenital anomalies in Saudi children: A community-based study", Annals of Saudi Medicine, 35, 107-110 (2015).

2- D. Huggard, D. G. Doherty and E. J. Molloy, "Immune dysregulation in children with down syndrome", Front Pediatr., 8, 73 (2020).

3- M. Dierssen, M. Fructuoso, M. M. De Lagrán, M. Perluigi and E. Barone, "Down syndrome is a metabolic disease: altered 
insulin signaling mediates peripheral and brain dysfunctions", Frontiers In Neuroscience, 14 (2020).

4- E. Hefti and J. G. Blanco, "Anthracyclinerelated cardiotoxicity in patients with acute myeloid leukemia and down syndrome: A literature review", Cardiovasc. Toxicol., 16, 5-13 (2016a).

5- E. Hefti and J. G. Blanco, "Pharmacokinetics of chemotherapeutic drugs in pediatric patients with down syndrome and leukemia", J. Pediatr. Hematol. Oncol., 38, 283-7 (2016b).

6- M. L. Palumbo and C. J. Mcdougle, "Pharmacotherapy of down syndrome", Expert. Opin. Pharmacother., 19, 18751889 (2018).

7- L. Patel, K. Wolter-Warmerdam and F. Hickey, "Patterns of behavior and medical comorbidities in down syndrome", Journal of Mental Health Research in Intellectual Disabilities, 1-14 (2020).

8- C. Dandara, M. Swart, B. Mpeta, A. Wonkam and C. Masimirembwa, "Cytochrome P450 pharmacogenetics in african populations: Implications for public health", Expert. Opin. Drug Metab. Toxicol., 10, 769-85 (2014).

9- T. S. Tracy, A. S. Chaudhry, B. Prasad, K. E. Thummel, E. G. Schuetz, X.-B. Zhong, Y.-C. Tien, H. Jeong, X. Pan and L. M. Shireman, "Interindividual variability in cytochrome P450-mediated drug metabolism", Drug Metabolism And Disposition, 44, 343-351 (2016).

10- U. M. Zanger and M. Schwab, "Cytochrome P450 enzymes in drug metabolism: Regulation of gene expression, enzyme activities, and impact of genetic variation", Pharmacol. Ther., 138, 103-41 (2013).

11- G. Magliocco, A. Thomas, J. Desmeules and Y. Daali, "Phenotyping of human Cyp450 enzymes by endobiotics: current knowledge and methodological approaches", Clinical Pharmacokinetics, 58, 1373-1391 (2019).

12- G. A. Keller, M. L. F. Gago, R. A. Diez and G. Di Girolamo, "In-Vivo phenotyping methods: Cytochrome P450 probes with emphasis on the cocktail approach", Curr. Pharm. Des., 23, 2035-2049 (2017).
13- J. O. Miners, P. I. Mackenzie and K. M. Knights, "The prediction of drugglucuronidation parameters in humans: Udp-glucuronosyltransferase enzymeselective substrate and inhibitor probes for reaction phenotyping and in-vitro / in-vivo extrapolation of drug clearance and drugdrug interaction potential. Drug Metabolism Reviews, 42, 196-208 (2010).

14- S. Gravel, J. L. Chiasson, F. Gaudette, J. Turgeon and V. Michaud, "Use of $4 \beta$ hydroxycholesterol plasma concentrations as an endogenous biomarker of Cyp3a activity: Clinical validation in individuals with type 2 diabetes", Clinical Pharmacology \& Therapeutics, 106, 831840 (2019).

15- S. R. Penzak and C. Rojas-Fernandez, "4 $\beta$ Hydroxycholesterol as an endogenous biomarker for Cyp3a activity: Literature review and critical evaluation", The Journal Of Clinical Pharmacology, 59, 611-624 (2019).

16- K. Hole, P. L. Heiberg, C. Gjestad, L. L. Mehus, Ø. Rø and E. Molden, "Elevated $4 \beta$-hydroxycholesterol/cholesterol ratio in anorexia nervosa patients", Pharmacology Research \& Perspectives, 6, E00430 (2018).

17- L. Naing, T. Winn and B. Rusli, "Practical issues in calculating the sample size for prevalence studies", Archives Of Orofacial Sciences, 1, 9-14 (2006).

18- J. Van Der Lee, J. Wesseling, M. Tanck and M. Offringa, "Efficient ways exist to obtain the optimal sample size in clinical trials in rare diseases", Journal of Clinical Epidemiology, 61, 324-330 (2008).

19- U. Diczfalusy, H. Nylen, P. Elander and L. Bertilsson, "4beta-Hydroxycholesterol, an endogenous marker of Cyp3a4/5 activity in humans", Br. J. Clin. Pharmacol., 71, 183-9 (2011).

20- J. G. Mcdonald, D. D. Smith, A. R. Stiles and D. W. Russell, "A comprehensive method for extraction and quantitative analysis of sterols and secosteroids from human plasma", Journal of Lipid Research, 53, 1399-1409 (2012).

21- A. De Matteo and P. Vajro,"Down syndrome and pediatric nonalcoholic fatty liver disease: A causal or casual 
relationship?", J. Pediatr., 189, 11-13 (2017).

22- M. J. De La Piedra, G. Alberti, J. Cerda, A. Cárdenas, M. A. Paul and M. Lizama,"High frequency of dyslipidemia in children and adolescents with down syndrome", Rev. Chil. Pediatr., 88, 595601 (2017).

23- K. Unachak, P. Tanpaiboon, Y. Pongprot, R. Sittivangkul, S. Silvilairat, P. Dejkhamron and J. Sudasna, "Thyroid functions in children with down's syndrome", J. Med. Assoc. Thai., 91, 5661 (2008).

24- R. A. Harvey and D. R. Ferrier, "Lippincott's Illustrated Reviews: Biochemistry", Philadelphia, Wolters Kluwer Health (2011).

25- S. J. Woolsey, M. D. Beaton, Y. H. Choi, G. K. Dresser, S. E. Gryn, R. B. Kim and R. G. Tirona, "Relationships between endogenous plasma biomarkers of constitutive cytochrome P450 3A activity and single-time-point oral midazolam microdose phenotype in healthy subjects", Basic \& Clinical Pharmacology \& Toxicology, 118, 284-291 (2016).

26- M. Tremblay-Franco, C. Zerbinati, A. Pacelli, G. Palmaccio, C. Lubrano, S. Ducheix, H. Guillou and L. Iuliano, "Effect of obesity and metabolic syndrome on plasma oxysterols and fatty acids in human", Steroids, 99, 287-292 (2015).

27- M. Kotlyar and S. Carson, "Effects of obesity on the cytochrome P450 enzyme system", International Journal of Clinical Pharmacology and Therapeutics, 37, 8-19 (1999).

28- M. Ulvestad, I. Skottheim, G. S. Jakobsen, S. Bremer, E. Molden, A. Åsberg, J. Hjelmesæth, T. Andersson, R. Sandbu and H. Christensen, "Impact of Oatp1b1, Mdr1, and Cyp3a4 expression in liver and intestine on interpatient pharmacokinetic variability of atorvastatin in obese subjects", Clinical Pharmacology \& Therapeutics, 93, 275-282 (2013).
29- J. Palle, B. M. Frost, G. Gustafsson, M. Hellebostad, J. Kanerva, E. Liliemark, K. Schmiegelow and G. Lonnerholm, "Etoposide pharmacokinetics in children treated for acute myeloid leukemia", Anticancer Drugs, 17, 1087-94 (2006).

30- C. M. Zwaan, G. J. Kaspers, R. Pieters, K. Hahlen, G. E. Janka-Schaub, C. H. Van Zantwijk, D. R. Huismans, E. De Vries, M. G. Rots, G. J. Peters, G. Jansen, U. Creutzig and A. J. Veerman, "Different drug sensitivity profiles of acute myeloid and lymphoblastic leukemia and normal peripheral blood mononuclear cells in children with and without down syndrome", Blood, 99, 245-51 (2002).

31- E. C. Bell, W. R. Ravis, H. M. Chan and Y. J. Lin, "Lack of pharmacokinetic interaction between St. John's wort and prednisone", Ann. Pharmacother., 41, 1819-24 (2007).

32- H. I. El-Subbagh and A. A. Al-Badr, "Chapter 2 Cytarabine", In: G. B. Harry (Ed.), "Profiles Of Drug Substances, Excipients And Related Methodology", Academic Press (2009).

33- M. Hassan, G. Oberg, H. Ehrsson, M. Ehrnebo, I. Wallin, B. Smedmyr, T. Totterman, S. Eksborg and B Simonsson, "Pharmacokinetic and metabolic studies of high-dose busulphan in adults", Eur. J. Clin. Pharmacol., 36, 525-30 (1989).

34- T. Kawashiro, K. Yamashita, X. J. Zhao, E. Koyama, M. Tani, K. Chiba and T. Ishizaki, "A study on the metabolism of etoposide and possible interactions with antitumor or supporting agents by human liver microsomes", J. Pharmacol. Exp. Ther., 286, 1294-300 (1998).

35- C. D. Stowe and S. J. Phelps, "Altered clearance of theophylline in children with down syndrome: A case series", J. Clin. Pharmacol., 39, 359-65 (1999).

36- P. J. Barnes, "Chapter 50 - Theophylline", Asthma And Copd (2 ${ }^{\text {nd }}$ Edn.). Oxford: Academic Press (2009). 


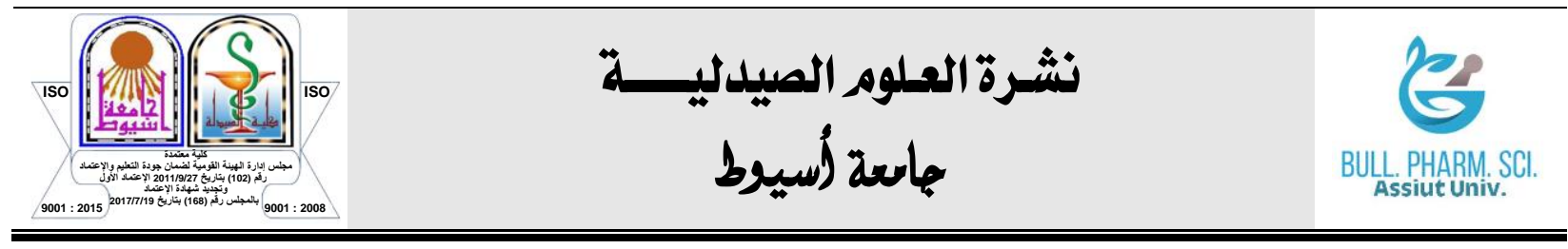

تحديد النشاط الظاهري لإززيمات الأيض في أطفال متلازمة داون باستخدام مؤشر حيوي داخلي

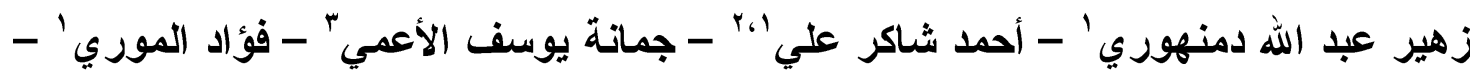

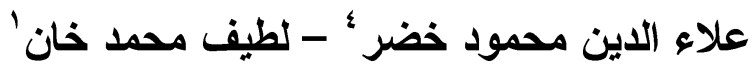

' قسم علم الأدوية ، كلية الطب ، جامعة الملك عبد العزيز ، المملكة العربية السعودية

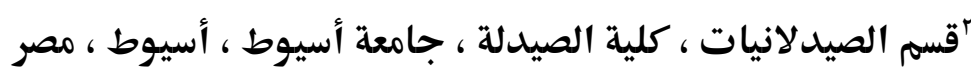

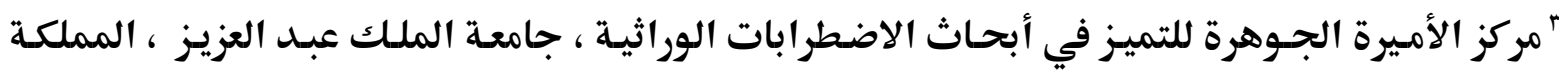
العربية السعودية ؛قمم الكيمياء الصيدلية ، كلية الصيدلة ، جامعة الملك عبد العزيز ، المملكة العربية السعودية

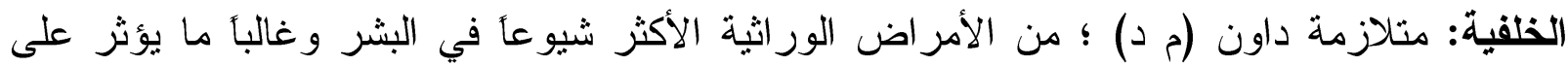

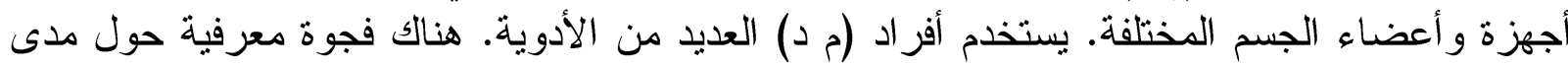

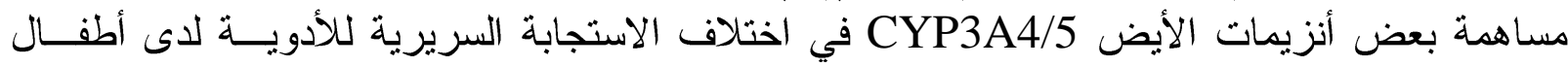

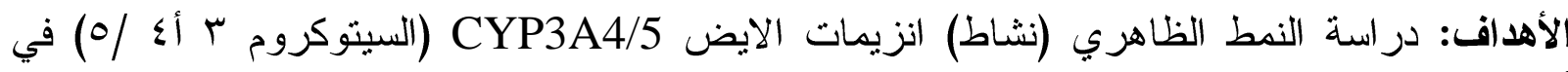

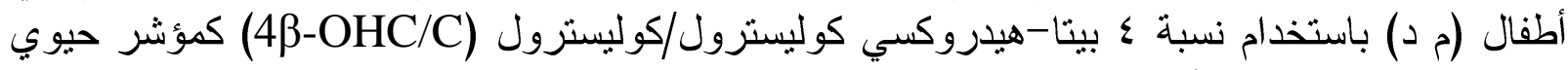
داخلي لنشاط انزيمات الأيض السابق ذابن ذكر ها.

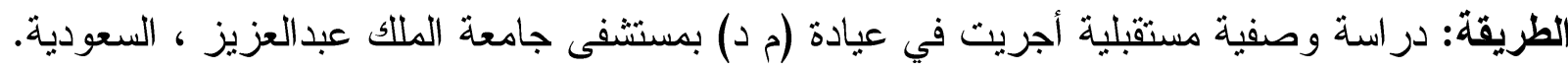

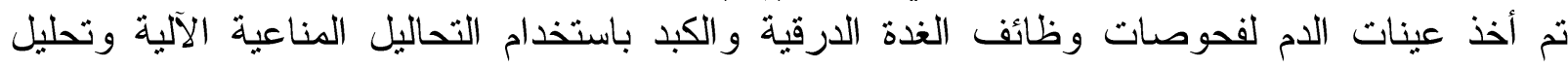

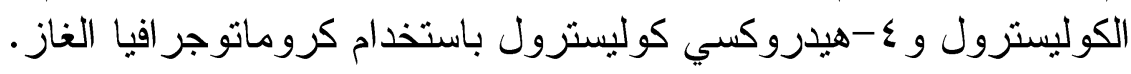

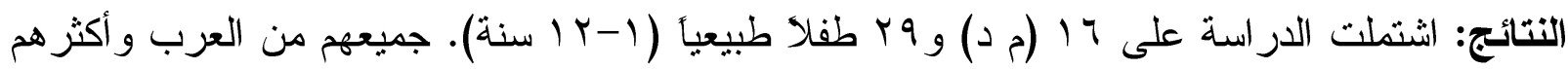

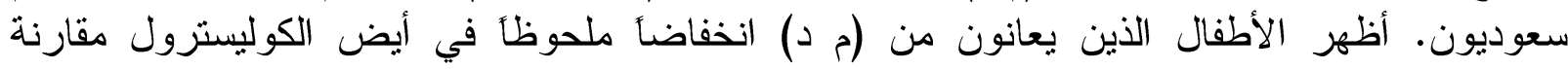

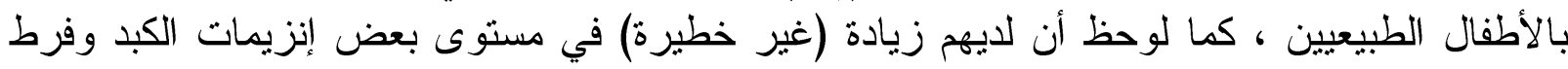
كوليسترول الدم.

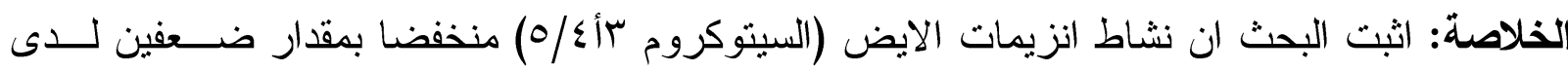

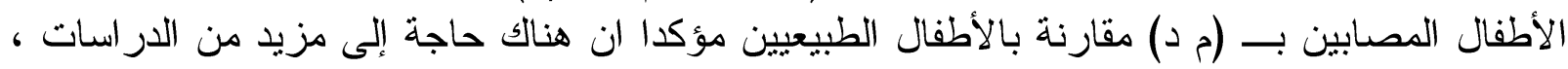
ومع ذلك ، يجب استخدام الأدوية بحذر مع أطفال (م د). 